\title{
Questes
}

\section{« La nuit » dans L'Espurgatoire seint Patriz de Marie de France}

\section{Myriam White}

\section{Q OpenEdition}

1 Journals

\section{Édition électronique}

URL : http://journals.openedition.org/questes/1941

DOI : 10.4000/questes. 1941

ISSN : 2109-9472

Éditeur

Les Amis de Questes

\section{Édition imprimée}

Date de publication : 15 janvier 2004

Pagination : 26-30

ISSN : 2102-7188

\section{Référence électronique}

Myriam White, « «La nuit » dans L'Espurgatoire seint Patriz de Marie de France », Questes [En ligne], 6 | 2004, mis en ligne le 01 janvier 2014, consulté le 15 septembre 2020. URL : http:// journals.openedition.org/questes/1941

\section{(C) Association des amis de "Questes »}


séparait de Dieu, et répand sa prière en présence du Seigneur ${ }^{30}$. Le Nuage de l'Inconnaissance est bien l'œuvre de la contemplation qui cherche à percer l'obscurité afin d'accéder à la lumière divine. Les religieux ont ainsi suivi au Moyen Age la parole de Job : «Après la Ténèbre, j'espère la Lumière » (Job, 17,12).

\title{
« La nuit » dans L'Espurgatoire seint Patriz de Marie de France
}

\author{
Myriam WHITE
}

L'Espurgatoire seint Patriz de Marie de France propose principalement le récit du voyage dans l'autre monde d'un chevalier, nommé Owein. Ce dernier cherche par ce moyen à faire pénitence des nombreux péchés qui lui font redouter le jugement de Dieu. Il entre dans une fosse révélée à saint Patrick, en Irlande, et il découvre successivement le purgatoire et le paradis terrestre. Au purgatoire, une obscurité inquiétante règne mais ce n'est pas celle de la nuit. Il s'agit davantage des ténèbres du Mal et de l'éloignement de Dieu. Dans l'autre monde que présente Marie, il n'existe d'ailleurs pas une temporalité qui puisse se mesurer comme la nôtre. Néanmoins la sortie de la fosse, après son périple souterrain, est tout de même pour le chevalier un retour symbolique vers la lumière du jour, comme en témoigne le vers 1903, « a la porte vint de cler jur ». C'est une sortie des ténèbres qui promet une vie renouvelée, plus lumineuse et

\footnotetext{
30 Guigues II, Lettre sur la vie contemplative, éd. du Cerf, 1970, p.145.
} 
purifiée du péché. Pourtant il est également directement question de la nuit dans le récit de l'aventure fabuleuse d'Owein. A diverses reprises, on trouve le terme « nuit » en association avec son antithèse, «jour », notamment aux vers 277, « nuit e jur fud en oreisuns » ou 317, « un jur e une nuit entiere ». Pour préparer le voyage dans l'autre monde, il faut prier et jeûner pendant un certain temps. De plus, la durée du séjour dans l'au-delà, pour qui en sort vivant, est d'un jour et d'une nuit. Cela constitue un cycle complet, en sorte que l'issue de cette durée permet d'envisager une renaissance. La nuit est alors la moitié du cycle et n'a pas une valeur singulière par rapport au jour. Toutefois, on doit peut-être lire une légère insistance sur la nuit comme temps de la purification et de l'exercice de la volonté du pénitent dans L'Espurgatoire. De fait, le motif de la veille est récurrent lorsque Marie traite des préparatifs au voyage pénitentiel ou de la vie de toute personne sainte. On en trouve des exemples aux vers 462 , « en veilles, en affliccïuns », 578, « orer, veiller e jeüner », ou 1910. La nuit peut permettre de s'amender, d'élever son âme qui ne se trouve plus détournée du sacré par les séductions du monde. L'épreuve de la veille montre que la foi peut transcender l'incarnation. La nuit de veille peut alors être le moment de la promesse d'une humanité sublimée et forte par et pour Dieu.

Le récit central consacré aux différents étapes de ce voyage s'accompagne d'homélies et de récits secondaires placés avant ou après la narration centrale et qui viennent l'appuyer. On y retrouve le terme «nuit» dans l'évocation de durées comportant des cycles complets, comme au vers 2031, «treis jurs e treiz 
nuiz l'ont tenu », qui précise le temps pendant lequel un moine a été enlevé par des démons. Mais il est plus significatif de relever d'autres emplois de «nuit» dans les récits secondaires. La nuit devient alors le moment des phénomènes étranges qui mettent aux prises notre monde et l'autre, le plus souvent démoniaque. De fait, le précédent moine est enlevé de nuit par les démons, comme le rapportent les vers 2023 à 2029,

El dortur vit apertement, une nuit, entre le covent, si cum il jut e dut dormir, les dïables a lui venir, qui corporelment le ravirent e del dortur le departirent, si ke li covenz nel sout mie.

Plusieurs courts récits relatent les expériences de religieux qui ont pu avoir la certitude de l'existence des démons, la nuit. Ainsi un ermite qui menait une vie exemplaire :

Chascune nuit, ço ne faut mie, ot les dïables assembler entur sun purpris e parler. (vv. 2098-2100)

Paradoxalement, les démons sont des êtres que l'on ne peut voir que dans l'obscurité de la nuit : «aneire après soleil couchant, / a veüe venent avant » (vv. 2101-2102) et «li seinz les veit apertement» (v. 2107). La nuit est davantage le moment d'une communication possible avec les forces du Mal, de l'affleurement d'un autre monde, que le moment d'une obscurité qui se voudrait réaliste. Elle est le temps propice à l'activité des démons qui tiennent par exemple leurs conseils : 
J'oï l'autre nuit veirement ço que jo vos dirrai briefment.

L'autre nuit furent ajusté

Li diable e ici assemblé. (vv. 2147-2150)

La nuit est aussi, pour le saint, le moment d'une révélation, que l'on devine permise par Dieu, des mystères des Ténèbres. Cela lui permettra de mettre en garde les autres hommes. Si la nuit prive de la lumière du jour, c'est qu'il faut alors ouvrir les yeux sur d'autres réalités.

Pourtant lorsque les démons décident de s'en prendre à un prêtre qui menait une existence exemplaire, ils ne l'attaquent pas la nuit mais le matin. Il choisissent de lui faire adopter une petite fille abandonnée, afin de causer sa chute lorsqu'il éprouvera un désir charnel pour la jeune femme qu'elle deviendra. Le bébé est déposé dans le lieu que l'homme pieux fréquente lors de ses prières matinales quotidiennes. D'une part, il est plus réaliste que l'homme trouve l'enfant lors de ses occupations habituelles, «si cum il soleit» (v. 2217), qu'à une heure incongrue. D'autre part, et surtout, les actes du matin semblent être l'aboutissement des réflexions et des projets malfaisants de la nuit des démons. De fait, ils se promettent que la chute du prêtre aura lieu un jour dit, « einz mïedi. Ke chascuns l'oie !» (v. 2249). Ils mettent en pratique le matin les mauvaises résolutions de la nuit. La nuit est donc le temps de la préparation, voire de la fomentation. En somme, « la nuit » dans L'Espurgatoire seint Patriz de Marie de France retrouve certaines valeurs héritées du christianisme, notamment dans les récits secondaires. Dans le récit central qui relate le voyage 
du chevalier Owein, il nous paraît plus malaisé de parler de la nuit car nous ne voulons pas la confondre avec l'obscurité. De plus, la temporalité de l'autre monde ne nous paraît pas pouvoir s'analyser dans les termes de nuit ou de jour, comme celle du nôtre. Autre monde, autre temps !

\section{Aux marges de la nuit. \\ Le voyage de l'âme dans l'au-delà et la symbolique du passage}

\section{Mattia CAVAGNA}

Dans l'imaginaire chrétien médiéval, la frontière entre la réalité terrestre et l'audelà est conçue comme une limite tout à fait perméable qui peut être franchie dans l'un ou l'autre sens. La nuit contribue ultérieurement à nuancer cette frontière : l'obscurité favorise les différents types de contacts entre les deux mondes, à savoir les apparitions des saints et des revenants, mais surtout les rêves et les voyages extatiques des hommes.

Entre ces deux dernières catégories de visions il existe des différences importantes qui se rapportent justement à la dimension nocturne. Si d'un côté les rêves comportent le sommeil du protagoniste, de l'autre les voyages dans l'au-delà impliquent, au contraire, un état de veille qui se traduit en un processus tout à fait dynamique : la séparation de l'âme du corps et son départ dans l'audelà. Nous voudrions concentrer notre analyse sur ce type d'expérience 